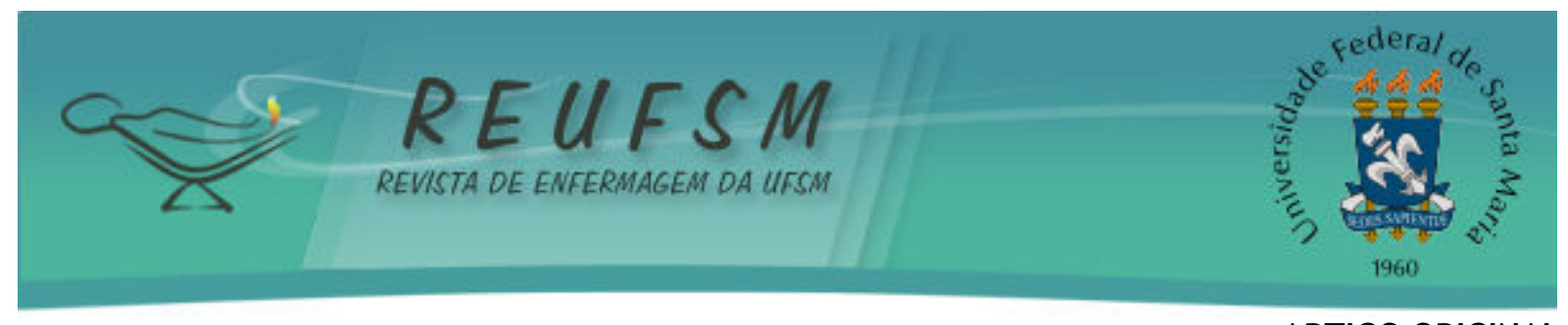

ARTIGO ORIGINAL

\title{
OS AFETOS NO PROCESSO DE TRABALHO GERENCIAL NO HOSPITAL: AS VIVÊNCIAS DO ENFERMEIRO*
}

\author{
THE AFFECTS IN THE MANAGERIAL WORKING PROCESS IN THE HOSPITAL: THE \\ EXPERIENCES OF THE NURSE
}

\begin{abstract}
AFECTOS EN EL PROCESO DE TRABAJO DE GESTIÓN EN EL HOSPITAL: EXPERIENCIA DEL ENFERMERO
\end{abstract}

\author{
Rogério Silva Lima ${ }^{1}$ \\ Eliana Bernardes Lourenço ${ }^{2}$
}

Doi: $10.5902 / 2179769212871$

RESUMO: Objetivo: compreender os sentimentos vivenciados pelos enfermeiros em função do exercício do gerenciamento no contexto hospitalar. Método: estudo de abordagem qualitativa, do tipo exploratório e descritivo com corte transversal, como referencial teórico foi utilizada a Teoria das Representações Sociais. Foram entrevistados dez enfermeiros por meio de um roteiro semi-estruturado. Os dados foram interpretados com base na análise do discurso, da linha da Psicologia Social, por meio da técnica dos Mapas de Associação de Ideias. Resultados: identificaram-se sentimentos predominantemente negativos reportados pelos enfermeiros em relação ao exercício de seu trabalho gerencial, relacionados aos determinantes organizacionais e sociais das representações do trabalho. Considerações finais: são necessárias outras investigações que se proponham ao aprofundamento na temática com metodologias pautadas na pesquisa-ação com vistas à melhoria dos processos de trabalho no ambiente hospitalar.

Descritores: Gerência; Administração hospitalar; Enfermagem.

ABSTRACT: Aims: to understand the feelings experienced by nurses in the exercise of management in the hospital wards. Method: qualitative, exploratory, descriptive and cross-sectional study. The theoretical framework used was the Social Representations Theory. Ten nurses were interviewed using a semi-structured script. The data were interpreted based on the discourse analysis of Social Psychology, through the technique of Maps of Association of Ideas. Results: it was identified that the feelings reported by nurses in regards to the exercise of managerial work are predominantly negative. Those feelings were related to organizational and social determinants of the representations of their work. Final considerations: other investigations that propose the deepening of the theme are necessary, using methodologies guided by action-research in order to improve the working processes in the hospital context.

Descriptors: Management; Hospital administration; Nursing.

RESUMEN: Objetivo: comprender los sentimientos experimentados por los enfermeros provocados por el ejercicio de gestión en el ámbito hospitalario. Método: estudio

\footnotetext{
"Artigo extraído da Dissertação de Mestrado "Gerenciamento em enfermagem no contexto hospitalar: o discurso do enfermeiro e sua equipe" apresentada ao Programa de Pós-graduação em Enfermagem da Universidade Federal de Alfenas - UNIFAL- MG, Brasil.

${ }^{1}$ Enfermeiro, Mestre em Enfermagem, Universidade Federal de Alfenas (UNIFAL-MG), Alfenas, Minas Gerais, Brasil. Email: rogerio.lima@unifal-mg.edu.br

${ }^{2}$ Psicóloga e Pedagoga, Doutora em Educação, Universidade Federal de Alfenas (UNIFAL-MG), Alfenas, Minas Gerais, Brasil.Email:elianabernardesloureco@gmail.com
} 


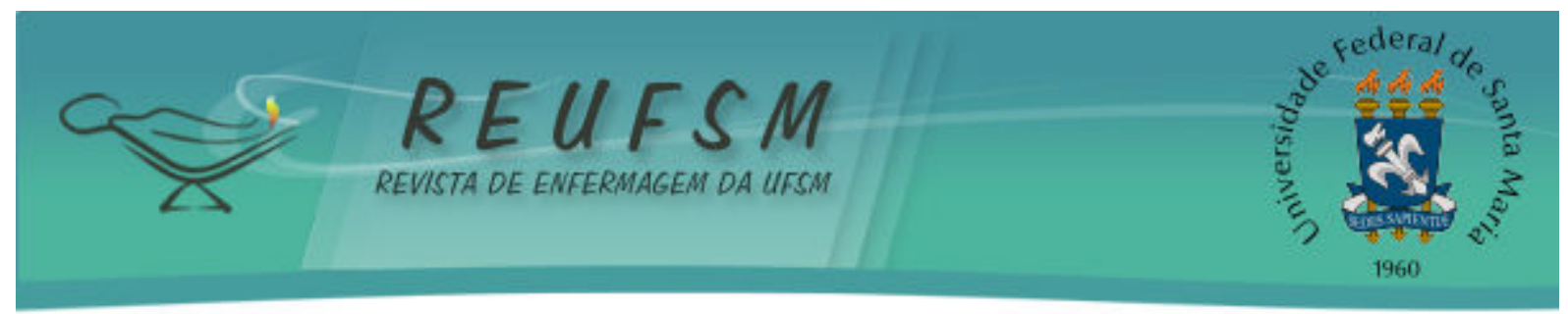

cualitativo, exploratorio y descriptivo de corte transversal, utilizando como marco teórico la Teoría de las Representaciones Sociales. Fueron entrevistados diez enfermeros mediante la tecnica de la entrevista semiestructurada. Los datos fueron interpretados con base en el análisis del discurso, en la corriente de la Psicología Social, através de la técnica de los Mapas de Asociación de Ideas. Resultados: se identificaron sentimientos predominantemente negativos reportados por los enfermeros en relación al ejercicio de su trabajo de gestión. Los sentimientos estan relacionados con los determinantes organizativos y sociales de las representaciones del trabajo. Consideraciones finales: Son necesarias otras investigaciones que propongan profundizar en el tema utilizando metodologías de la investigación-acción, con el fin de mejorar los procesos de trabajo en ambiente hospitalario.

Descriptores: Gerencia; Administracion hospitalaria; Enfermería.

\section{INTRODUÇÃO}

A gênese do trabalho gerencial do enfermeiro remete aos primórdios da Enfermagem Moderna, influenciada pela divisão social e técnica do trabalho no contexto de uma sociedade pautada pelos pressupostos capitalistas. Nesse processo, o enfermeiro foi se apropriando das atividades administrativas, cujo objetivo é propiciar meios e instrumentos capazes de garantir a qualidade da assistência de enfermagem. ${ }^{1}$

No âmbito hospitalar, cada vez mais tem sido exigido do enfermeiro conhecimentos, competências e habilidades para o exercício da gerência do processo de trabalho. ${ }^{2}$ No entanto, autores têm demonstrado a dificuldade dos profissionais na articulação entre a dimensão assistencial, cujo núcleo é o cuidado de enfermagem, e a dimensão gerencial, que assume como objeto a organização do trabalho e os recursos humanos em enfermagem. ${ }^{1}$

No cenário nacional, apesar dos progressos da área, encontram-se com frequência instituições hospitalares regidas por modelos gerenciais clássicos, pautados em abordagens burocráticas e prescritivas, que atribuem ao enfermeiro apenas a função administrativa. ${ }^{3}$ Os hospitais, nesse paradigma, privilegiam a tecnologia e a técnica, desconsiderando os aspectos humanos e a contribuição do trabalhador e desfavorecendo o manejo de questões que envolvam a subjetividade, impossibilitam ao enfermeiro lidar adequadamente com suas emoções. ${ }^{4}$

Nesse arcabouço, o trabalhador pode caminhar para a produção de desgaste, mesmo porque, no modelo hegemônico, marcadamente biologicista, os aspectos da saúde no trabalho apenas recebem a devida atenção depois de já instalado o processo de adoecimento. ${ }^{5}$

Aliado a isso, sabe-se que a maioria dos serviços hospitalares brasileiros que prestam serviços ao Sistema Único de Saúde (SUS) precisa manter os padrões assistenciais diante de uma demanda crescente à custa de um financiamento progressivamente reduzido.

Nessa conjuntura adversa, o enfermeiro desenvolve suas atividades que transitam entre aquelas de assistência ao paciente e as responsabilidades gerenciais requeridas pelas organizações, na interseção com os processos de trabalho dos demais servidores, produzindo um serviço consumido no ato de sua produção, marcado pela interação humana e pelo trabalho afetivo. No entanto, nas circunstâncias atuais do capital, que se pauta pelos critérios da melhor performance, da flexibilidade, da polivalência e da competitividade, existe a tendência da não valorização do enfermeiro, com consequentes agravos à sua saúde física ou psíquica. ${ }^{6}$ Nessa perspectiva, o hospital é capaz de gerar formas de sofrimento e/ou prazer e torna-se um ambiente profícuo para o adoecimento profissional. ${ }^{4,7}$

É nesse contexto que o grupo de atores, no caso os enfermeiros, elabora as ideias e as imagens a respeito de sua prática gerencial. Infere-se que o enfermeiro, ao exercer a gerência no contexto hospitalar, objetiva sua subjetividade na inter-relação com os sujeitos do cuidado 


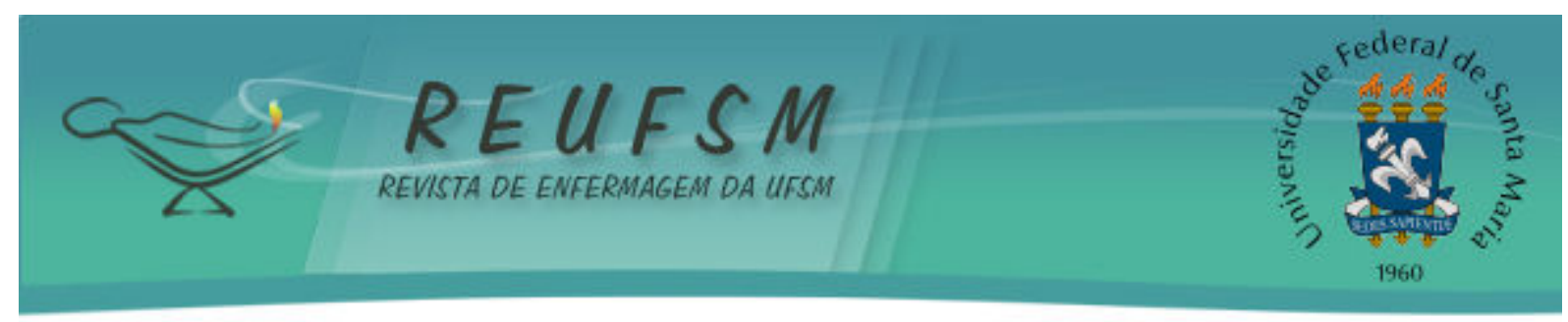

e com a organização do trabalho. Essa subjetividade exteriorizada, também a partir das emoções, pode intervir na lógica do processo de trabalho no sentido da produção de saúde ou da potencialização do desgaste. ${ }^{5}$

Nesse sentido, conhecer os sentimentos envolvidos no processo de trabalho gerencial em unidade hospitalar pode favorecer a compreensão das vivências do enfermeiro nesse campo, na medida em que os afetos relacionados às construções simbólicas são capazes de indicar o posicionamento dos atores sociais na teia das relações que ocorrem na esfera da operacionalização do trabalho. Essa aproximação pode contribuir para dar visibilidade às necessidades dos profissionais e abrir espaço para discussão e elaboração de estratégias de promoção da saúde que envolvam a reordenação dos fluxos e processos, levando em conta aspectos intersubjetivos que também implicam na qualidade da assistência e na satisfação no trabalho.

Ressalta-se que são incipientes, em grande parte das organizações hospitalares, as iniciativas que buscam estabelecer um espaço de cuidado aos profissionais do cuidado. ${ }^{5}$ Portanto, são necessárias pesquisas que se dediquem à compreensão desse fenômeno sob a ótica dos atores envolvidos.

Tendo em vista a necessidade de aprofundamento nessa temática, indaga-se: quais são os sentimentos vivenciados pelos enfermeiros em relação ao exercício da gerência nas unidades hospitalares? Essa pesquisa teve por objetivo compreender os sentimentos vivenciados pelos enfermeiros em relação ao exercício da gerência no contexto hospitalar.

\section{MÉTODO}

Estudo de abordagem qualitativa, do tipo exploratório e descritivo, desenvolvido em um hospital geral e filantrópico do Sul de Minas Gerais (MG). Essa instituição oferece atendimento ambulatorial e internações nas especialidades de clínica médica, cirurgia, ginecologia e obstetrícia, pediatria e terapia intensiva. Conta com serviço de pronto atendimento, centro cirúrgico, ortopedia e nefrologia. Nesse espaço, os enfermeiros exercem funções relacionadas ao gerenciamento da assistência de enfermagem e supervisão direta dos colaboradores técnicos e auxiliares de enfermagem.

No sentido de compreender quais os sentimentos vivenciados pelos enfermeiros em relação à sua atribuição gerencial, adotou-se a Teoria das Representações Sociais (TRS), elaborada por Serge Moscovici como referencial teórico. ${ }^{8}$ Entende-se que essa teoria pode favorecer a compreensão do processo de como ocorre a construção do conhecimento de um grupo específico a partir do qual se molda o comportamento do referido grupo, tendo em vista o solo cultural das produções das histórias de vida tanto no nível individual quanto no social, permitindo a aproximação para com o mundo dos significados das ações, das relações e da subjetividade.

A representação social designa uma forma de ver a realidade, pois ao direcionar a ação do indivíduo favorece a remodelagem e reconstituição dos elementos do meio em que o comportamento tem sua expressão. ${ }^{8} \mathrm{~A}$ ênfase recai na natureza do conhecimento e situa as representações sociais como conhecimento prático, buscando a superação da clivagem entre Ciência e senso comum, localizando este último na teia de significados capazes de recriar a realidade social. Entende-se que o processo de elaboração de representações sociais tem lugar no âmbito do vivido, na interface entre as permanências históricas e culturais e as produções dialógicas do cotidiano. Como estruturas cognitivo-afetivas são capazes de orientar os comportamentos e propiciar as condições para a construção de um real-comum. ${ }^{9}$

As representações sociais possuem como uma de suas dimensões internas a atitude, que se traduz pela orientação global do indivíduo ou grupo em relação ao objeto representado, 


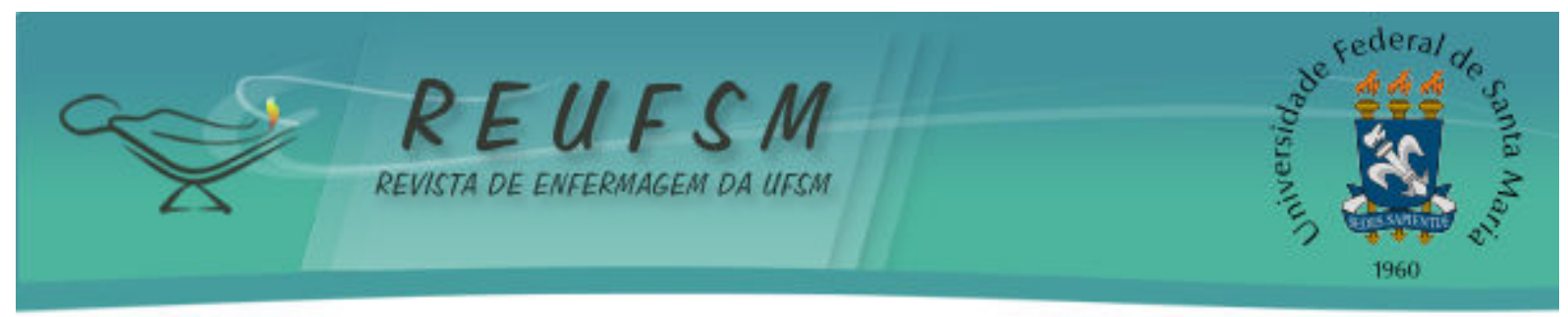

podendo assumir o caráter favorável ou desfavorável. Desse modo, o indivíduo representa algo apenas após ter adotado um posicionamento e em função da posição tomada. ${ }^{8}$ Infere-se que a aproximação para com os afetos experimentados pelos enfermeiros em relação a sua função gerencial pode fornecer indícios da posição assumida por esses atores no contexto de produção das representações. Assim, acredita-se que o investimento afetivo dos sujeitos também se inscreve no processo de elaboração das representações socialmente compartilhadas.

A amostra foi não probabilística e por conveniência. Foram entrevistados dez enfermeiros gerentes de unidade de internação do Serviço de Enfermagem do mencionado hospital, que congregava um total de 13 elementos.

Elegeram-se os seguintes critérios de inclusão: ser enfermeiro gerente de unidade de internação e concordar em participar da pesquisa por meio da assinatura do Termo de Consentimento Livre e Esclarecido (TCLE). Por ocasião do convite à participação da pesquisa, um enfermeiro estava de férias, um se recusou a participar do estudo e um foi entrevistado para realização do pré-teste do roteiro de entrevista, não sendo incluído na amostra.

Para coleta de dados foi utilizado um roteiro de entrevista semi-estruturada composto por questões que se propunham a investigar como o enfermeiro se sentia na condição de gerente de uma unidade de internação e porque, em sua opinião, esses afetos eram experimentados.

A coleta de dados foi realizada no período de dezembro de 2011 a janeiro de 2012. Para o tratamento e análise dos dados, foi utilizada a Análise do Discurso, na perspectiva da psicologia social, por meio do Mapa de Associação de Ideias (MAl). ${ }^{9}$ Nessa perspectiva, situamse os fenômenos não apenas na ótica do intrapsíquico, mas na esfera do social e do interpessoal. $O$ foco de análise se volta à busca de padrões na linguagem associados a uma atividade, aos lugares comuns e aos significados interrelacionados na construção das versões de acontecimento e na justificativa de certas práticas sociais pelos portadores do discurso. ${ }^{10}$

0 trabalho de interpretação seguiu os seguintes passos: transcrição da entrevista, leitura flutuante do material transcrito associada à escuta do material gravado, retorno aos objetivos da pesquisa e o mapeamento dos discursos por meio dos temas significantes identificados. Nesse mapeamento, as entrevistas são dispostas em colunas, mantendo a sequência das falas, no entanto, permeando os diversos eixos e sub-eixos temáticos representados cada qual por uma coluna.

0 eixo do MAl que organizava os discursos dos enfermeiros em relação aos sentimentos que emergem no exercício da gerência permeou dois sub-eixos que foram denominados "Afetos Positivos" e "Afetos Negativos". Esse modo de organização possibilitou, por meio de uma leitura vertical e horizontal dos sub-eixos, o acesso ao conjunto de afetos que permeiam o exercício gerencial do enfermeiro e a associação entre esses afetos e as representações de gerência circulantes no imaginário social do grupo estudado.

Foram respeitados os preceitos éticos estabelecidos pela Resolução 196/96 do Conselho Nacional de Saúde. O estudo foi aprovado pelo Comitê de Ética e Pesquisa da Universidade Federal de Alfenas - MG, sob o número de protocolo 207/2011. Para preservar a privacidade e o anonimato, os participantes foram identificados pela letra E seguida do numeral arábico.

\section{RESULTADOS E DISCUSSÃO}

Nesse estudo, pôde-se perceber que os enfermeiros reportavam sentimentos preponderantemente negativos em relação às demandas de seu processo de trabalho gerencial. Por meio da análise dos discursos, foi possível identificar que os afetos negativos se agrupavam em torno das representações de gerenciamento desvinculado das ações de 


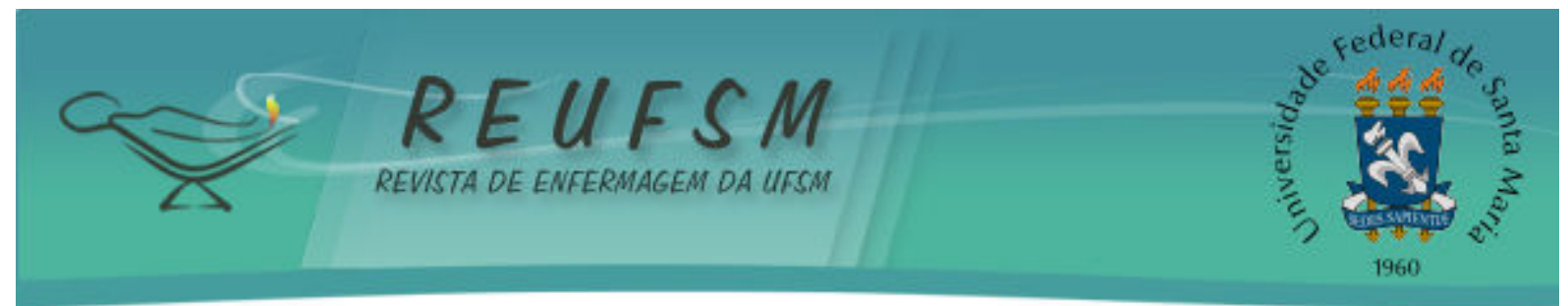

cuidado direto. Estudos têm reportado que os enfermeiros de diversas regiões do país apontam como estafante sua rotina de trabalho. ${ }^{7,11}$

[...] Você experimenta num dia só vários tipos de sentimentos, de ansiedade principalmente, impotência, raiva, decepção [...] a gente sente impotente, que poderia ter feito mais e faz menos, tem momento que acha que fez além da capacidade [...] Isso gera instabilidade emocional na gente sabe? Por exemplo estresse, sentimento de culpa, às vezes até desentendimento com a equipe $e$ com a gente interiormente, você briga constantemente. É sempre isso no final de uma jornada às vezes tenho a sensação de que eu não cumpri a minha missão naquele dia. (E1)

Nossa! É bem cansativo, é bem cansativo porque quase tudo cai em cima da enfermeira. Tudo, tudo até a parte administrativa, tudo dependem da gente, os funcionários são novos, é você tem que algumas vezes você tem que largar mão e ir lá e fazer por eles, ensinar ali naquela hora [...] Estressada, cansada [risos], nervosa, eu sinto até frustração, porque tem hora que parece que o meu serviço mesmo eu não fiz. Eu acho que é isso mesmo que eu estou sentindo, às vezes eu fico frustrada. A gente está esgotada, a gente é o para raio, então eles sabem, você é o enfermeiro então tudo vai em você. (E3)

Chama a atenção o modo como o sentimento de frustração parece perpassar o contexto da prática gerencial do enfermeiro. Esse sentimento parece ser relacionado à sobrecarga de funções e ao modo como ocorre o processo de trabalho gerencial desvinculado do processo de trabalho assistencial. Nesse modus operandi, a prática profissional é representada de modo desconexo e descaracterizada, configurando as atividades do enfermeiro como um trabalho alienado na perspectiva dos seus atores.

Esse modelo organizacional, que favorece com que o enfermeiro se distancie do objetivo de seu trabalho, que deveria priorizar a assistência, posiciona o profissional num conflito afetivo, a partir do qual ele passa a não se sentir satisfeito com os resultados de suas atividades e tampouco se sente capaz de empreender rotas eficazes de mudança.

[...] Mas é isso que desanima eu aqui sabe? Tem hora que eu desanimo porque eu acho que não vai mudar [...] eu não consigo ver a autonomia do enfermeiro. O enfermeiro não está fazendo nada [...] o serviço não está aparecendo entendeu? (E4)

[...] às vezes vem o sentimento de não conseguir atingir os objetivos que eu queria atingir [...] Insatisfação de não conseguir atender o objetivo pelo qual o paciente está aqui entendeu? O foco principal do paciente estar aqui, do tratamento, isso eu fico insatisfeita, de não conseguir dar um atendimento ideal para esse paciente [...]. (E8)

Ah, é mais aflição e assim, é sensação de impotência. Porque às vezes você deseja resolver aquilo da melhor forma possível, mas você não tem condições para aquilo. (E10) 


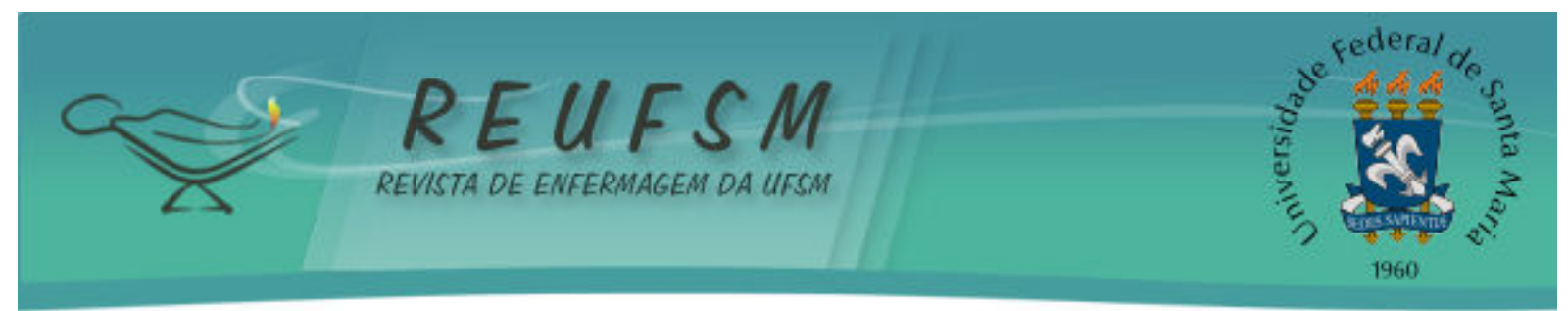

Nesse sentido, autores apontam que a função de administrador da equipe de enfermagem e de organizador do trabalho nas unidades de assistência pode favorecer sentimentos de culpa, incompetência, desqualificação, insatisfação para com as atividades desenvolvidas e a falta de reconhecimento. ${ }^{11}$ Além do mais, o desenvolvimento das atividades gerenciais, na perspectiva do cumprimento das demandas dos profissionais médicos, pode contribuir para a destituição da autonomia do enfermeiro. Enfatiza-se que, no imaginário social a respeito do ofício do enfermeiro, encontra-se, como imagem hegemônica, a de um profissional cujas funções se submetem àquelas atribuídas pelo médico. ${ }^{12}$ Esse universo simbólico é capaz de colaborar e retroalimentar sentimentos negativos a respeito da falta de autonomia no exercício da enfermagem.

Estudos apontam que o trabalhador tem seu estresse laboral reduzido quando pode contar com um supervisor no processo de trabalho. ${ }^{6} \mathrm{~A}$ esse respeito, observou-se que, correlacionado às representações de seu trabalho gerencial, o enfermeiro reporta 0 sentimento de insegurança que parece ser relacionado à ausência de conhecimento técnico-operacional em face às exigências da instituição.

[...] no início eles me jogaram também no pronto- socorro e no CTI [Centro de Terapia Intensiva], eu trabalhava a noite, nossa eu sentia uma angústia tão grande, tão grande! Porque eu não tinha segurança naquilo que eu fazia [...] Insegurança técnica e até de poder coordenar a equipe de enfermagem. (E2)

Às vezes assim eu fico meio insegura, às vezes eu fico pensando será que eu vou saber administrar, vou saber gerenciar mesmo a unidade, Ah! Algum procedimento que tem que fazer $e$ eu não tenho experiência, é ter que recorrer a alguém. (E5)

As falas dos enfermeiros remetem a um estado emocional de conflitos que se configura por frustração, cansaço, sensação de impotência e dever não cumprido. Estes qualificadores expressados pelos participantes podem indicar exaustão emocional e baixo nível de realização no trabalho. Tais achados podem estar relacionados à Síndrome de Burnout, à qual os enfermeiros estão sujeitos pelos determinantes da própria profissão, pelas características das condições de trabalho no contexto hospitalar e também pela ambiguidade e conflitos de papéis. ${ }^{13}$ Dessa ótica, o trabalhador da enfermagem vivencia especificidades no trabalho que contribuem para o surgimento do estresse, do sofrimento e, consequentemente, de doenças. Entre tais especificidades, destacam-se: a divisão do trabalho em três categorias, a não valorização social do trabalho, a rigidez da personalidade e da hierarquia, as relações ora autoritárias e hostis para com os membros da equipe e pacientes, ora submissas ao poder médico e a obrigatoriedade de desenvolver postura de líder. ${ }^{11} \mathrm{~A}$ partir desses elementos, o enfermeiro objetiva sua função gerencial na conjuntura de um posicionamento caracterizado pelo investimento afetivo predominantemente negativo e desfavorável.

No entanto, é preciso reconhecer que os sentimentos de inadequação profissional podem assumir duplo sentido. Se, por um lado, tais sentimentos podem determinar uma postura conformista, que não possibilita a mudança de comportamento, por outro, os mesmos sentimentos podem servir como força propulsora para mudança da práxis, desde que adequadamente catalisados. Para tanto, um dos caminhos possíveis para superação das contradições desse embate seria o favorecimento de espaços dialógicos intrainstitucionais. $^{5}$ 


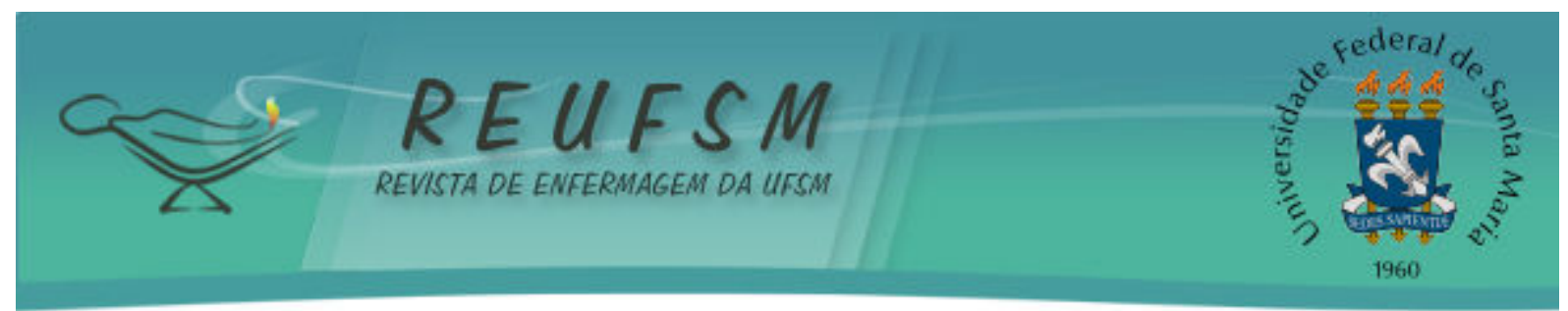

Nesse sentido, o sofrimento afetivo no trabalho não é apenas resultado de um processo que une a subjetividade ao trabalho, mas pode indicar o ponto de origem para mudança na medida em que é capaz de favorecer a busca por meios de superação e resistência. ${ }^{5,14}$

Assim, a abertura da gerência de enfermagem a espaços de discussão poderia favorecer a tomada de consciência dos enfermeiros quanto à necessidade de mudança, pois para a implantação de novos modelos de gestão, é imprescindível a percepção dos envolvidos sobre a necessidade de mudança. ${ }^{15}$

Entre os afetos que qualificam a representação da prática gerencial do enfermeiro, foram encontrados também afetos positivos.

[...] eu gosto disso, eu me sinto bem, eu me desenvolvi assim, com os profissionais lá dentro muito bem, então eu não tive nenhum problema com medico, com técnico, eu não tive nenhum problema até hoje então eu me sinto bem lá dentro [...] Então muitos médicos vem me ensinar algumas coisas, então eu me sinto assim, é bastante amparada, pelos médicos e pelos funcionários. (E5)

Ah eu gosto [sorrindo] eu me sinto bem, eu sinto assim que é aquilo mesmo que eu sempre quis [...] Eu gosto, me sinto bem, assim com o pessoal, é aquilo mesmo que eu sempre quis, estar ali atuando naquela área. (E6)

É um sentimento bom, de saber que você está ajudando, que você está fazendo a sua parte. (E7)

Muitas vezes de realização pelo serviço que às vezes eu consegui executar com qualidade da minha parte, quando as coisas dão certo. Eu sinto assim realização, a parte do paciente falando muito obrigado, sair satisfeito do atendimento que foi realizado. (E8)

[...] de alegria, de satisfação, por estar sendo útil naquele momento. (E9)

Dois elementos nos discursos dos enfermeiros permitem inferir o posicionamento assumido pelos sujeitos, a partir do qual eles parecem elaborar a representação de gerência como uma imagem marcada pelo aspecto positivo dos afetos: a proximidade com a equipe e a proximidade com os pacientes.

Por um lado, a aproximação para com os pacientes ocorre no sentido de ser útil e de ajudar. Essas características, inscritas no discurso possível, ancorado nas raízes históricas do desenvolvimento da profissão, perpassando a fundação do sistema de ensino nightingaliano e configurando a enfermagem numa perspectiva altruísta e religiosa, ${ }^{16-17}$ parecem exercer influência no modo como os enfermeiros organizam os afetos, que assumem o caráter positivo na medida em que os profissionais se afiliam às representações de gerenciamento que os aproximam das atividades de cuidado. Observa-se que, no Brasil, a ideologia da enfermagem desde sua origem significava abnegação, obediência e dedicação. Nesse paradigma, o enfermeiro não deveria exercer a crítica social, mas sim consolar e socorrer as vítimas da sociedade. Mesmo depois da sistematização do ensino de enfermagem no país, foi persistente a vinculação às ordens religiosas, tanto na orientação dos serviços como na manutenção das escolas. ${ }^{17}$ 


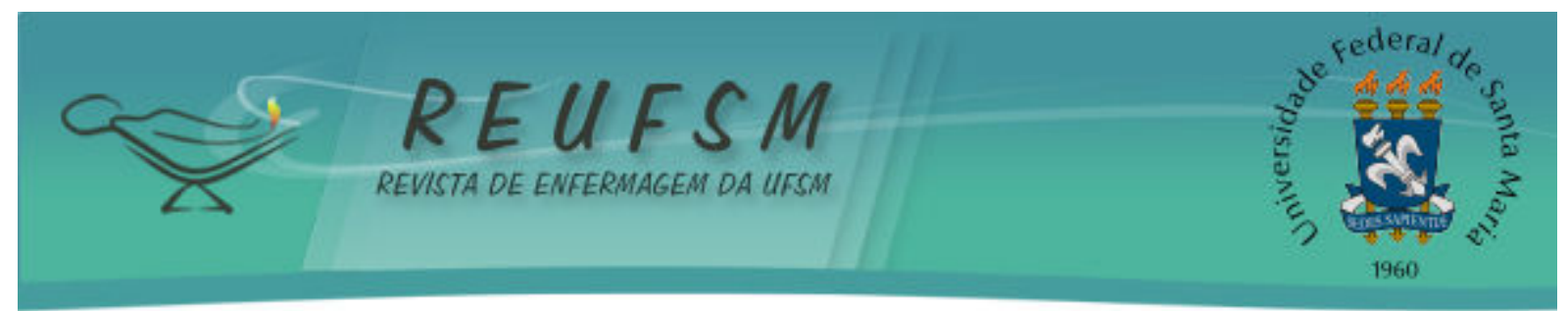

Por outro lado, a retomada do paciente como sujeito sobre o qual deve incidir a ação da enfermagem pode indicar uma possibilidade de reinserção do cuidado na prática gerencial do enfermeiro. O reencontro do enfermeiro com o cuidado é capaz de motivá-lo porque, nesse espaço, o profissional pode observar o resultado concreto do seu trabalho, ao passo que, distante do cuidado, o enfermeiro talvez não seja capaz de reconhecer a finalidade de seu processo gerencial. $^{18}$ Assim, alternativas que visem articular as atividades de gerenciamento ao processo assistencial podem contribuir para produção de prazer, melhoria dos níveis de satisfação e redução do stress no processo de trabalho. ${ }^{19-20}$

Quanto à proximidade com a equipe, o discurso aponta para as relações informais no cotidiano de trabalho. Sabe-se que a estrutura informal coexiste com a estrutura formal da organização e é também capaz de configurar o modo de trabalho dos atores envolvidos. Portanto, a estrutura informal não deve ser desconsiderada, uma vez que a participação de todos os integrantes da equipe pode favorecer o surgimento de novas lideranças capazes de promover espaços para reflexão, permitindo a conformação de uma estrutura formal com relações mais horizontais que favoreçam a implantação de estratégias para integração das ações de gerencia e cuidado e para redução do estresse no ambiente de trabalho. . $6,20^{2}$

\section{CONSIDERAÇÕES FINAIS}

Esse estudo possibilitou a compreensão dos sentimentos vivenciados pelos enfermeiros em relação ao exercício do processo de trabalho gerencial no contexto hospitalar. Os afetos reportados pelos enfermeiros assumem predominantemente o aspecto negativo e qualificam a representação de gerência a partir das dificuldades vinculadas à sobrecarga de função, à dificuldade de conciliação do processo de trabalho gerencial com o assistencial e ao não reconhecimento social de sua prática.

Contudo, no mesmo universo representacional foi possível observar afetos positivos que se aliam às representações de gerenciamento traduzidas a partir da reaproximação do enfermeiro para com o cuidado e ao estabelecimento de relações de trabalho mais horizontais com a equipe.

Como limite desse estudo ressalta-se o pequeno número amostral, no entanto, pôde-se observar a convergência dos achados com os da literatura.

O trabalho de enfermagem, como prática social, histórica e culturalmente datada, ocorre também a partir da intersubjetividade de seus atores. Portanto, acredita-se que talvez sejam necessárias posturas pautadas em outros pressupostos epistemológicos que busquem também a compreensão das relações e emoções envolvidas no espaço do trabalho, contextualizado a partir de sua dimensão social e política.

Considera-se a necessidade de outras investigações que se proponham ao aprofundamento na temática com metodologias pautadas na pesquisa-ação com vistas à melhoria dos processos de trabalho no ambiente hospitalar.

\section{REFERÊNCIAS}

1. Hausmann $M$, Peduzzi $M$. Articulação entre as dimensões gerencial e assistencial do processo de trabalho do enfermeiro. Texto \& Contexto Enferm [Internet]. 2009 [acesso em 2014 jan/jun 8];18(2):258-65. Disponível em: http://www.scielo.br/pdf/tce/v18n2/08.pdf.

2. Manenti SA, Ciampone MHT, Mira VL, Minami LF, Soares JMS. O processo de construção do perfil de competências gerenciais para enfermeiros coordenadores de área hospitalar. Rev Esc Enferm USP [Internet]. 2012 [acesso em 2013 dez 2];46(3):727-33. Disponível em: http://www.scielo.br/pdf/reeusp/v46n3/27.pdf. 


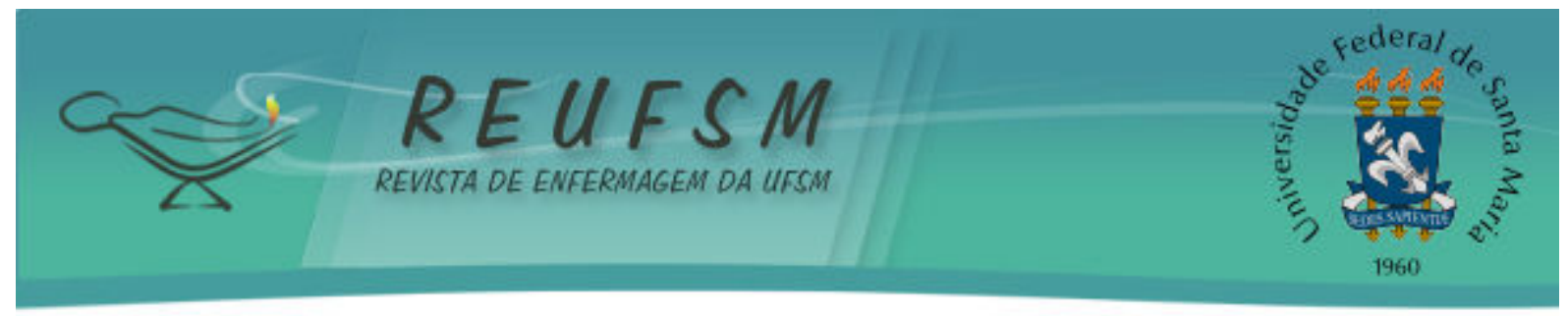

3. Caveião C, Hey AP, Montezeli JH. Administração em enfermagem: um olhar na perspectiva do pensamento complexo. Rev Enferm UFSM [Internet]. 2013 [acesso em 2014 maio 1]:3(1):79-85. Disponível em: http://dx.doi.org/10.5902/217976927176.

4. Traesel ES, Merlo ARC. Trabalho imaterial no contexto da enfermagem hospitalar: vivências coletivas dos trabalhadores na perspectiva da Psicodinâmica do Trabalho. Rev Bras Saúde Ocup [Internet]. 2011 [acesso em $2014 \mathrm{fev}$ 3];36(123):40-55. Disponível em: http: //www.redalyc.org/pdf/1005/100518631005.pdf.

5. Azambuja EP, Pires DEP, Vaz MRC, Marziale, MH. É possível produzir saúde no trabalho da enfermagem? Texto \& Contexto Enferm [Internet]. 2010 out [acesso em 2013 dez 2];19(4):658-66. Disponível em: http://www.scielo.br/pdf/tce/v19n4/08.pdf.

6. Ribeiro RP, Martins JT, Marziale MHP, Robazzi MLCC. O adoecer pelo trabalho na enfermagem: uma revisão integrativa. Rev Esc Enferm USP [Internet]. 2012 [acesso em 2014 jan 12];46(2):495-504.

http://www.scielo.br/pdf/reeusp/v46n2/a31v46n2.pdf.

Disponível em:

7. Paula GS, Reis JF, Dias LC, Dutra VFD, Braga ALS, Cortez EA. O sofrimento psíquico do profissional de enfermagem da unidade hospitalar. Aquichan [Internet]. 2010 [acesso em 2014 fev 8];10(3):267-79. Disponível em: http: / / www.redalyc.org/articulo.oa?id=74116984008.

8. Moscovici S. A representação social da psicanálise. Rio de Janeiro (RJ): Zahar; 1978.

9. Spink MJP. Desvendando as teorias implícitas: uma metodologia de análise das representações sociais. In: Guareschi P, Jovchelovitch S, organizadores. Textos em representações sociais. Petrópolis (Rj): Vozes; 1994. p. 117-48.

10. Nogueira C. Análise(s) do discurso: diferentes concepções na prática de pesquisa em psicologia social. Psic Teor e Pesq [Internet]. 2008 [acesso em 2014 maio 3];24(2):235-42. Disponível em: http://dx.doi.org/10.1590/S0102-37722008000200014.

11. Marcolan JF. Trabalho e produção de sofrimento nas organizações de saúde. In: Santos AS, Miranda SMRC, organizadores. A enfermagem na gestão em atenção primária à saúde. Barueri (SP): Manole; 2007. p. 198-224.

12. Samaniego VC, Cárcamo S. The nursing image and professional identity. The future of a construction. Invest Educ Enferm [Internet]. 2013 [acesso em 2014 abr 28];31(1):54-62. Disponível em: http://aprendeenlinea.udea.edu.co/revistas/index.php/iee/article/view/10566/13137.

13. Galindo RH, Feliciano KVO, Lima RAS, Souza Al. Síndrome de Burnout entre enfermeiros de um hospital geral da cidade do Recife. Rev Esc Enferm USP [Internet]. 2012 [acesso em 2014 jan 8];46(2):402-7. Disponível em: http://www.scielo.br/pdf/reeusp/v46n2/a21v46n2.pdf.

14. Dejours C. Subjetividade, trabalho e ação. Rev Prod [Internet]. 2004 [acesso em 2013 fev 12];14(3):27-34. Disponível em: http: //www.scielo.br/../v14n3a03.pdf.

15. Bernardes A, Cecílio LCO, Évora YDM, Gabriel CS, Carvalho MB. Collective and decentralized management model in public hospitals: perspective of the nursing team. Rev Latinoam Enferm [Internet]. 2011 [acesso em 2013 fev 12];19(4):1003-10. Disponível em: http://www.scielo.br/pdf/rlae/v19n4/20.pdf.

16. Brito AMR, Brito MJM, Gazzinelli MFC, Montenegro LC. Representações sociais de discentes de graduação em enfermagem sobre "ser enfermeiro". Rev Bras Enferm 


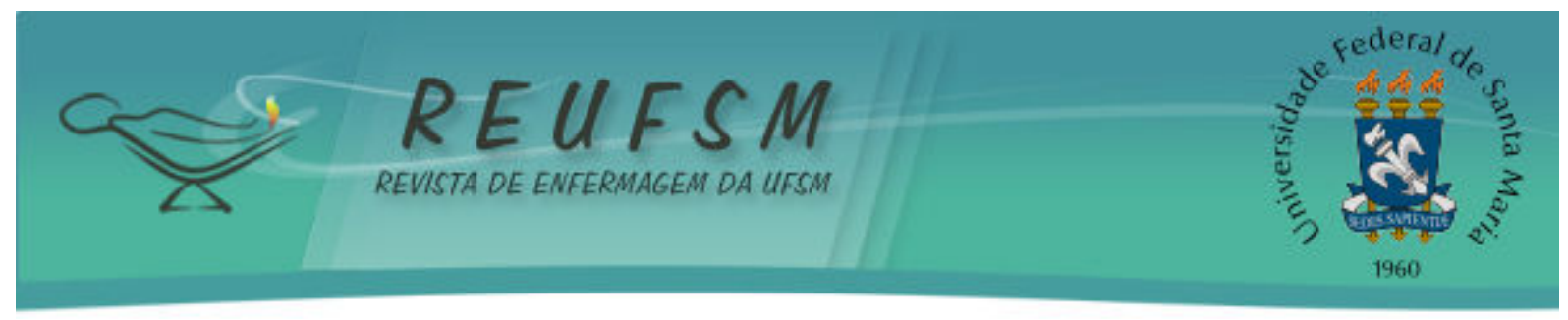

[Internet] 2011 [acesso em 2014 maio 4];63(3):527-35. Disponível em: http: / / www. redalyc.org/articulo.oa?id=267019943017.

17. Germano RM. Educação e ideologia da enfermagem no Brasil. São Paulo (SP): Cortez; 1984.

18. Xavier-Gomes LM, Barbosa TLA. Trabalho das enfermeiras-gerentes e a sua formação profissional. Trab Educ Saúde [Internet]. 2011 [acesso em 2014 abr 30];9(3):449-59. Disponível em: http://www.scielo.br/pdf/tes/v9n3/v9n3a06.pdf.

19. Santos JLG, Prochnow AG, Silva DC, Silva RM, Leite JL, Erdmann AL. Prazer e sofrimento no exercício gerencial do enfermeiro no contexto hospitalar. Esc Anna Nery [Internet]. 2013 [acesso em 2014 maio 5];17(1):97-103. Disponível em: http://dx.doi.org/10.1590/S1414-81452013000100014.

20. Menzani G, Bianchi ERF. Stress dos enfermeiros de pronto socorro dos hospitais brasileiros. Rev Eletrônica Enferm [Internet]. 2009 [acesso em 2014 maio 5];11(2):327-33. Disponível em: http://www.fen.ufg.br/fen_revista/v11/n2/pdf/v11n2a13.pdf.

Data de recebimento: $10 / 02 / 2014$

Data de aceite: $24 / 06 / 2014$

Contato com autor responsável: Rogério Silva Lima

Endereço postal: Universidade Federal de Alfenas, Escola de Enfermagem. Rua Gabriel Monteiro da Silva, $n^{\circ}$ 700, Centro. CEP: 37130000 - Alfenas, MG - Brasil.

E-mail: rogerio.lima@unifal-mg.edu.br 